\title{
The Effect of High Intensity Interval Training with Genistein on Biomechanical Properties of Femur Bone in Elderly Female Rats
}

\author{
Farideh Keikhosravi $^{1}$, Farhad Daryanoosh ${ }^{1 *}$, Maryam Koushkie Jahromi ${ }^{1}$, Javad Nemati ${ }^{1}$ \\ 1. Department of Sport Sciences, Shiraz University, Iran
}

\section{Article Type:}

Original Article

\section{Article History:}

Received: 22 Jan 2020

Revised: 11 Feb 2020

Accepted: 1 Mar 2020

\section{*Correspondence:}

Farhad Daryanoosh, Department of Sport Sciences, Shiraz University, Iran daryanoosh@shirazu.ac.ir

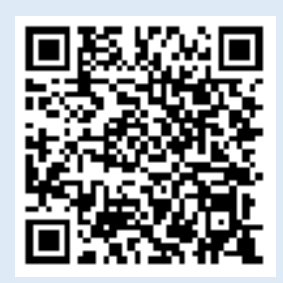

DOI: 10.29252/jorjanibiomedj.8.1.51

\begin{abstract}
Background and objective: Proper exercise and nutrition can help prevent bone disorders in old age, therefore present study aimed to investigate the effects of high intensity interval training (HIIT) with genistein $(\mathrm{Ge})$ on biomechanical properties of femur bone in elderly female rats.

Methods: In this experimental study, 40 elderly female rats with mean age of 18- 24 months and mean weight of $220.15 \pm 15.28 \mathrm{~g}$ were divided into five groups of eight rats including: 1) control (C), 2) sham (Sh), 3) HIIT, 4) HIIT + Ge, and 5) Ge. During eight weeks groups 3 and 4 performed HIIT for three sessions per week with an intensity of 90 to $95 \%$ of maximum oxygen consumption (VO2max) in high intensity intervals and 40 to $45 \% \mathrm{VO} 2 \mathrm{max}$ in low intensity intervals and groups 4 and 5 received $60 \mathrm{mg} / \mathrm{kg} /$ day Ge peritoneally. Maximum bending strength (Fmax) measured with three- point bending test and serum levels of calcium $(\mathrm{Ca})$ and phosphorus were measured by o-Cresolphthalein and molybdate methods, respectively. Shapiro- Wilk, one way ANOVA with Tukey's post- hoc tests were used for analysis of data ( $\mathrm{P} \leq 0.05)$.

Results: HIIT ( $\mathrm{P}=0.02), \mathrm{Ge}(\mathrm{P}=0.001)$ and $\mathrm{HIIT}+\mathrm{Ge}(\mathrm{P}=0.001)$ significantly increased Fmax also $\mathrm{Ge}(\mathrm{P}=0.04)$ and $\mathrm{HITT}+\mathrm{Ge}(\mathrm{P}=0.03)$ had more favorable effect on increasing Fmax compare to HIIT nevertheless HIIT, Ge and HIIT+Ge had not significant effect on $\mathrm{Ca}$ and phosphorus $(\mathrm{P} \geq 0.05)$.

Conclusion: Although HIIT and Ge alone can enhance Fmax in femur of elderly female rats, nevertheless HIIT+Ge has more favorable effect on increase of Fmax compare to HIIT.
\end{abstract}

Keywords: High Intensity Interval Training, Genistein, Biomechanical Properties, Femur

Copyright $\subseteq$ 2018, Jorjani Biomedicine Journal has published this work as an open access article under the terms of the Creative Commons Attribution License (http://creativecommons.org/licenses/by-nc/4.0/) which permits noncommercial uses of the work while it is properly cited. 


\section{Introduction}

Elderly people have limited regenerative abilities and are more prone to disease, syndromes and boredom than other adults. With the increase of life expectancy and sedentary life style of people, various diseases have caused the quality of life of the elderly to decrease and they face physical problems. Therefore, regarding to increase in age, the prevention of menopausal complications is of particular importance. Menopause is associated with many early and late complications that lead to a decrease in women's quality of life. Among the problems of this period of the time are cardiovascular diseases, osteoporosis and mental problems (such as depression and anxiety), and therefore need a new range of health care (1). Decreased estrogen levels and physical activity are among the main causes of osteoporosis (2). Numerous therapies, such as hormone replacement therapy and physical activity programs, have been developed to prevent osteoporosis. Due to the fact that medicinal plants have fewer side effects than synthetic drugs, researchers are looking for herbal compounds for the treatment or prevention of diseases (3). Phytoestrogens are a group of plant- derived compounds whose structural similarity to estrogens has led to act like estrogens. In fact, their structural similarity to estrogens allows them to bind to estrogen receptors and have estrogenic effects on the body. Isoflavones are a group of flavonoid phytoestrogens and the most common of which is genistein $(\mathrm{Ge})$, which is found in large amounts in soybeans (4). The therapeutic effects of $\mathrm{Ge}$ in enhancing bone tissue (5), increasing serum levels of progesterone and estradiol in the elderly rats (6), and improving osteoporosis (7) have been confirmed in several studies. On the other hand, it seems that the elderly people are usually faced with a decrease in the ability to perform daily activities, and the most important factor in increasing the quality of life in these people depends on the ability to perform daily activities. Therefore, exercises as a non-invasive and low-cost treatment method have been considered by health researchers (8). Regular and aerobic exercises can improve bone disorders by increasing joint metabolism, synovial fluid, and antioxidant and anti-inflammatory effects (8). Numerous studies have shown that improvement in bone density, bone absorption, and bone resorption occurs after exercise (9). Studies have shown that the use of complementary methods to improve or prevent the progressive effects of bone disorders to improve the quality of life of the elderly has been considered, but their mechanism of action is not yet fully understood (9). Although it is not yet clear how intensities of exercises are effective in stimulating bone metabolism, nevertheless a review of studies shows that moderate to high intensity exercises, with short intervals in water or land can be used as part of preventive and treatment programs for bone disorders (10). High-intensity interval training (HIIT) has favorable effects due to its high intensity and low-intensity intervals, and is now used as a new exercise. HIIT has been reported to improve osteopontin and bone mineral markers in young women (11), as well as increase PTH and ALP levels in rats (12). Given that reduced mobility and immobility in the elderly people can lead to bone disorders in these people. Therefore, due to the occurrence of bone disorders in elderly women and the long course of treatment and economic costs of the problems that will follow for these people; using complementary therapies to achieve better results is a worthwhile solution. Therefore regarding to 
protective effects of HIIT and Ge and the absence of a study that has examined the interactive and simultaneous effects of HIIT and $\mathrm{Ge}$ on bone tissue in the elderly condition; present study aimed to investigate the effect of HIIT with Ge on biomechanical properties of femur bone in elderly female rats.

\section{Materials and Methods}

In this experimental study, 40 Sprague Dawley rats with mean age of 18- 24 months and mean weight of $220.15 \pm 15.28 \mathrm{~g}$ were purchased and kept in animal laboratory with humidity of 45 to $55 \%$, dark-light cycle of 12 12 hours and temperature of $23 \pm 2{ }^{\circ} \mathrm{C}$ and free access to food and water. To adapt, rats were kept for one week under standard conditions and free access to food and water. Then rats randomly divided into five groups of eight rats including: 1) control (C), 2) sham (dimethyl sulfoxide (DMSO) + normal saline) (Sh), 3) HIIT, 4) HIIT + Ge, and 5) Ge. During eight weeks groups 3 and 4 performed HIIT for three sessions per week with an intensity of 90 to $95 \%$ of maximum oxygen consumption (VO2max) in high intensity intervals and 40 to $45 \% \mathrm{VO} 2 \mathrm{max}$ in low intensity intervals (13) and groups 4 and 5 received $60 \mathrm{mg} / \mathrm{kg} / \mathrm{kg}$ Ge dissolved in DMSO + normal saline peritoneally (6). Forty- eight hours after the last training session and Ge administration rats were anesthetized (with 10 hours overnight fasting) with ketamine $(50 \mathrm{mg} / \mathrm{kg})$ and xylazine $(10 \mathrm{mg} / \mathrm{kg})$, and after blood sampling and extracting bone tissue as well as transferring them to laboratory; $\mathrm{Ca}$ and phosphorus were measured by $\mathrm{o}$ Cresolphthalein and molybdate methods, respectively. Also Maximum bending strength (Fmax) measured by three- point bending test.

\section{HIIT protocol}

HIIT performed three sessions per week on rodent treadmill for eight weeks. The main trainings were as follow: based on the calculated aerobic power at the beginning of each week, the rats performed nine 2-minute high intensity intervals with intensity of 9095\% VO2max along with 1-minute active recovery intervals with intensity of $50 \%$ VO2max. It should be noted that at the beginning and end of the training program, 4 minutes of warm-up and cooling down with an intensity of 45 to $55 \%$ VO2max was added to the time of the main trainings (13).

\section{Ge administration}

To prepare Ge, at first Ge (Sigma Aldrich; with economic code of CAS NO: 446-72-0 and BACH NO: 20150605) was dissolved in DMSO and then diluted using normal saline and $60 \mathrm{mg} / \mathrm{kg} /$ day was injected intraperitoneally(6).

\section{Aerobic power}

To evaluate the aerobic power, at first the rats warmed up for five minutes on a treadmill at speed of six meters per minute with slope of zero degrees, then every three minutes, the speed increased by three meters per minute until the animals reached exhaustion and could no longer continue. The criterion for reaching VO2max was the inability of the rats to continue the training protocol and three consecutive collisions (within one minute) to the end of treadmill, so the VO2max was obtained by using the running speed (13).

\section{Femur biomechanical testing}

Maximum bending strength (Fmax) measured with three- point bending test (SANTAM device, Iran). To perform the test, the femur bone was placed on the support bases of 
device from both ends and the vertical force was applied to the longitudinal axis of the bone (by the system operator) in the anteriorposterior direction, in the middle of the bone. The operating speed of the system operator was $5 \mathrm{~mm}$ per minute and the pressure continued until the bone was broken. By plotting the force- change length curve, the maximum bending strength of the bone was calculated in Newton.

\section{Ca and phosphorus measurement method}

Blood samples were collected and clot within 15 minutes at room temperature, then centrifuged for six minutes at $1500 \mathrm{rpm}$. Ca and phosphorus were measured by $\mathrm{o}-$ Cresolphthalein and molybdate methods, respectively using Pars Azmoon kits (Pars Azmoon Co., Tehran, Iran). All kits were used according to the manufacturer's instructions. Biochemical tests were performed by a Biolis 24i Premium system (Tokyo, Japan).

\section{Statistical analysis}

Shapiro- Wilk test was used for investigation of normal distribution of data and one way
ANOVA with Tukey's post- hoc test was used for analysis of data in Graph pad PRISM.8.3.0 software $\quad(\mathrm{P} \leq 0.05)$. The researchers received introduction letters from Shiraz Medical University with code IR.SUMS.REC.1399.409.

\section{Results}

The Ca, phosphorus and Fmax levels in five groups of research are presented in figure 1-3 respectively. The results of one way ANOVA test showed that there were no significant differences in $\mathrm{Ca}(\mathrm{P}=0.24)$ and phosphorus $(\mathrm{P}=0.95)$ levels between five study groups (Figure 1 and 2) nevertheless there was significant difference in Fmax levels between five study groups $(\mathrm{P}=0.001)$. The results of Tukey's post- hoc test showed that there was no significant difference in Fmax levels between $\mathrm{C}$ and $\mathrm{Sh}$ groups $(\mathrm{P}=0.99)$ nevertheless Fmax levels in HIIT $(\mathrm{P}=0.02)$, $\mathrm{Ge}(\mathrm{P}=0.001)$ and $\mathrm{HIT}+\mathrm{Ge}(\mathrm{P}=0.001)$ groups were significantly higher than $\mathrm{C}$ group also in Ge $(\mathrm{P}=0.04)$ and HIIT+Ge $(\mathrm{P}=0.03)$ groups were significantly higher than HIIT group (Figure

$3)$.

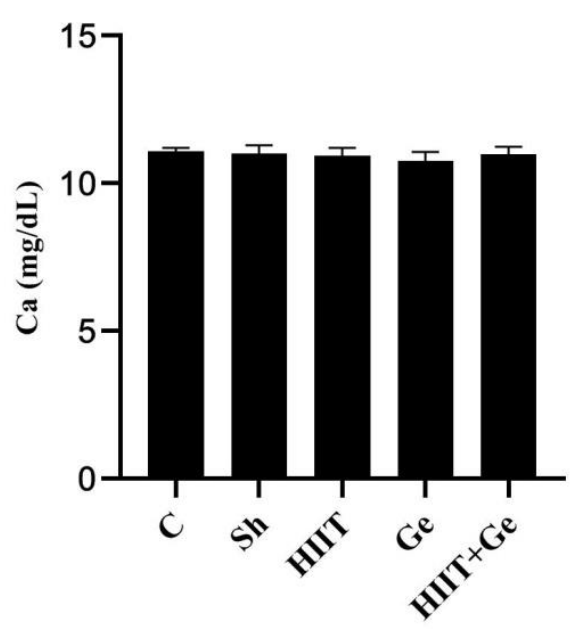

Figure 1: Ca levels in five groups of study

C: control, Sh: sham, HIIT: high intensity interval training, Ge: genistein 


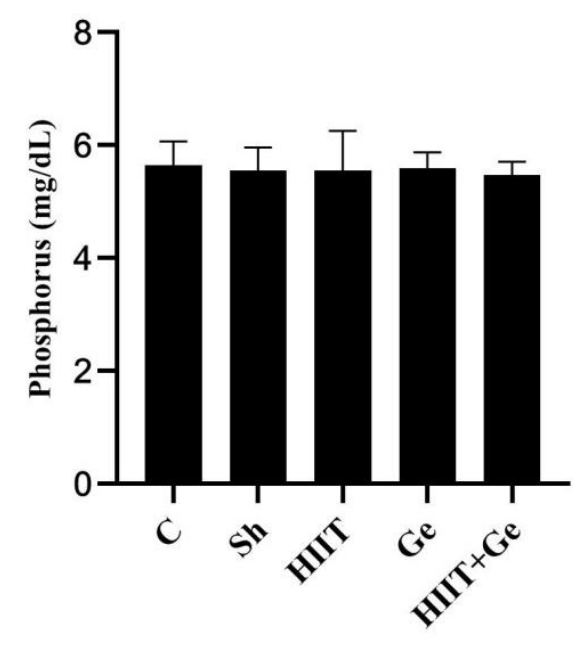

Figure 2: Phosphorus levels in five groups of study

C: control, Sh: sham, HIIT: high intensity interval training, Ge: genistein

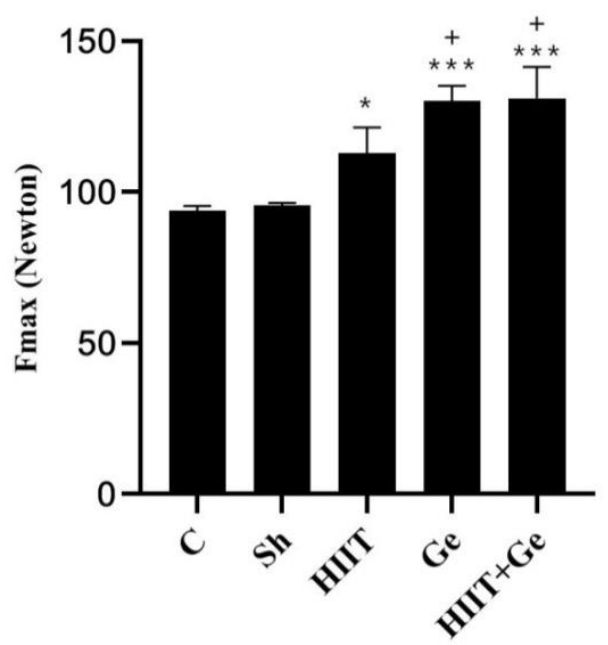

Figure 3: $F_{\max }$ levels in five groups of study $* * * \mathrm{P} \leq 0.001 ; * \mathrm{P} \leq 0.05$ Significant increase compare to $\mathrm{C}$ group

$+\mathrm{P} \leq 0.05$ Significant increase compare to HIIT group

C: control, Sh: sham, HIIT: high intensity interval training, Ge: genistein

\section{Discussion}

The results of the present study showed that HIIT did not have a significant effect on serum $\mathrm{Ca}$ and phosphorus levels, but significantly increased bone strength in elderly rats. Researchers have shown that there is a significant relationship between bone metabolism as well as extracellular $\mathrm{Ca}$ and phosphate; because bone is made up of a hard tissue which increase in deposition of $\mathrm{Ca}$ salts increases its strength. Ca salts make up a significant percentage of the weight of bone. As bone tissue has the highest exchange of organic matter with extracellular fluid, an increase in extracellular $\mathrm{Ca}$ and phosphorus with the mechanism of osteoblast formation leads to an increase in hydroxyapatite (with the formula Ca10 (PO4) $6(\mathrm{OH}) 2$ ) uptake, also increase in compressive and tensile strength of the bone $(14,15)$. Researchers believe that exercise can increase bone 
metabolism, strength and density via increasing testosterone production, the number of vitamin D receptors, and the modulation of calcitonin and parathyroid hormones (16); also, reabsorption of $\mathrm{Ca}$ in the intestines and increase in serum levels of vitamin $\mathrm{D}$ following exercise is one of the important adaptations to endurance training, which probably occurs with the mechanism of increasing the gene expression of $\mathrm{Ca}$ transporters in the kidneys and intestines (17), but changes in serum $\mathrm{Ca}$, phosphorus and bone metabolic markers are depend on the duration of exercise. In this regard, two days of exercise significantly increased serum $\mathrm{Ca}$, phosphorus and $\mathrm{Ca}$ /phosphorus ratio levels in elderly mice, while no significant change in these markers was reported after 3 and 8 weeks of exercise, nevertheless in line with the present study, bone density and strength significantly increased after long-term exercise in 16-month-old mice (16). Researchers have shown that exercise modulates the parathyroid hormone levels, but has no significant effect on $\mathrm{Ca}$ and phosphorus in young men (18); also, combined endurance and strength trainings increased bone strength by reducing parathyroid hormone levels, reducing inflammatory cytokines, and increasing osteocalcin (19).

The results showed that Ge consumption had no significant effect on $\mathrm{Ca}$ and phosphorus levels, nevertheless significantly increased bone strength in elderly rats. Researchers have shown that $\mathrm{Ge}$ can activate bone metabolic pathways due to its estrogen-like conditions (5). In addition, the $\mathrm{Ge}$ consumption increases bone density, minerals and strength by activation of osteoblasts, increasing the expression of estrogen receptors, increasing the insulin-like growth factor-1 (IGF-1) levels and its receptor at the level of bone cells as well as increasing the level of osteoprotegerin (OPG)/receptor activator of nuclear factor $\kappa \mathrm{B}$ ligand (sRANKL) (OPG/sRANKL) ratio (20). In this regard, $4.5 \mathrm{mg} / \mathrm{kg}$ and $18 \mathrm{mg} / \mathrm{kg} \quad \mathrm{Ge}$ consumption by modifying parathyroid hormone increased bone alkaline phosphatase and osteocalcin as well as increased bone density and strength, so that $18 \mathrm{mg} / \mathrm{kg} \mathrm{Ge}$ had a greater effects compared to $4.5 \mathrm{mg} / \mathrm{kg}$ nevertheless there were no differences in $\mathrm{Ca}$ and phosphorus levels in ovariectomized rats (5). In another study, $5 \mathrm{mg} / \mathrm{kg} \quad \mathrm{Ge}$ consumption for two months significantly increased mineral mass, strength, bone alkaline phosphatase and decreased carboxyterminal collagen cross links in rats with glucocorticoid-induced osteoporosis (20). Also $54 \mathrm{mg} /$ day Ge consumption significantly reduced sRANKL levels, increased OPG and OPG/sRANKL ratio in postmenopausal women with osteoporosis (21) and $10 \mathrm{mg} / \mathrm{kg}$ Ge consumption for 6 weeks significantly increased mineral mass, strength, alkaline phosphatase, osteocalcin, OPG and decreased RANKL (22). Differences in age and baseline levels of variables appear to be the reasons for differences in the results of reported studies. However, in a study $10 \mathrm{mg} / \mathrm{kg} \mathrm{Ge}, 50 \mathrm{mg} / \mathrm{kg}$ $\mathrm{Ge}, 250 \mathrm{mg} / \mathrm{kg}$ soybean and $500 \mathrm{mg} / \mathrm{kg}$ soybean enhanced the serum levels of $\mathrm{Ca}$, phosphorus, alkaline phosphatase, and osteocalcin in ovariectomized rats (23). The main reason for the difference in results, seems to be due to baseline levels of metabolic markers, so that $\mathrm{Li}$ et al., (22) in contrast with study of Hafez et al.,(23), did not use healthy control group (for investigate the effects of ovariectomy on the research variables).

The results also showed that HIIT simultaneously with Ge consumption did not have a significant effect on serum levels of $\mathrm{Ca}$ 
and phosphorus, but significantly increased bone strength in elderly rats. Also the results showed that bone strength in Ge group was significantly higher than HIIT group (130.2 vs 112.8) as well as in HIIT+Ge group was significantly higher than HIIT group (131.0 vs 112.8). Regarding to results of present study it appears that $\mathrm{Ge}$ administration has more favorable effect on increase of bone strength compared to HIIT. Combination of exercise and diet with a favorable amount of $\mathrm{Ca}$ and phosphorus can increase $\mathrm{Ca}$, phosphorus, and bone turnover (16). Exercise and $\mathrm{Ge}$ consumption improve $\mathrm{Ca}$, phosphorus and $\mathrm{Ca} /$ phosphorus ratio, and the number of vitamin D receptors as well as modulate the calcitonin and parathyroid hormones by increase estrogen levels and expression of estrogen receptors $(16,24)$. Also Ge increases bone density and strength by activation of osteoblasts, increased expression of estrogen receptors, IGF-1 and its receptor (20). Regarding to interactive effects, in line with present study endurance training and Ge consumption improved bone density and strength in ovariectomized mice (24); endurance training along with $600 \mathrm{mg} / \mathrm{kg} \mathrm{Ge}$ administration increased the mineral mass, bone density and strength in obese rats (25); also exercise along with $12 \mathrm{mg} / \mathrm{kg} \mathrm{Ge}$ administration significantly increased bone density and strength in ovariectomized rats (26). Regarding to the effects of parathyroid hormone, calcitonin, bone alkaline phosphatase and osteocalcin in regulation of $\mathrm{Ca}$ and phosphorus metabolism; one of the limitations of the present study is the lack of measurement of these variables along with measure the stiffness, $\varepsilon$ Fmax, and WRm. Therefore, it is suggested that in future studies, researchers measure these variables in addition to exercise and $\mathrm{Ge}$ consumption. Also its suggested that future studies evaluate bone geometry and histomorphometry parameters such as compact bone area, spongy bone area, trabecular separation area, number of osteocyte, femoral neck anteriorposterior diameter, and femoral neck length.

\section{Conclusion}

Although HIIT and Ge alone can enhance Fmax in femur of elderly female rats, nevertheless HIIT+Ge has more favorable effect on increase of Fmax compare to HIIT.

\section{Acknowledgment}

Considering the fact that the present study is a part of the doctoral dissertation approved by University of Shiraz, the authors of this article express their gratitude and appreciation for the spiritual support of the Research and Technology Department of this university. 


\section{References}

1. Tadayon Najafabadi M, Shalikar Z, Adedi P, Bamshad Z. The impact of omega-3 fatty acids on depression of menopausal women: a randomized double-blind clinical trial. J Arak Univ Med Sci. 2013;16(1):16-23.

2. Dubnov-Raz G, Pines A, Berry EM. Diet and lifestyle in managing postmenopausal obesity. Climacteric. 2007;10(sup2):38-41. [DOI: 10.1080/13697130701586428]

3. Zar A, Hosseini SA, Homaion A. Effect of eight-week aquagymnastic training on liver enzymes and lipid profile of middle-aged women. 2016;

4. Iranmanesh $\mathrm{S}$, Vahdati A, Afrouz $\mathrm{T}$. Comparison of the effects of ethinyl estradiol and genistein on serum lipids and lipoproteins of hypercholestrolemic male rats. Physiol Pharmacol. 2006;10(2):159-64.

5. Miao Q, Li J-G, Miao S, Hu N, Zhang J, Zhang $\mathrm{S}$, et al. The bone-protective effect of genistein in the animal model of bilateral ovariectomy: roles of phytoestrogens and PTH/PTHR1 against postmenopausal osteoporosis. Int $\mathrm{J}$ Mol Sci. 2012;13(1):56-70. [DOI:10.3390/ijms13010056]

6. Chi XX, Chu XL, Zhang T, Cao LK. Effect of genistein on the gene expressions of androgen generating key enzymes StAR, P450scc and CYP19 in rat ovary. Pol J Vet Sci. 2019;279-86.

7. Sehmisch S, Hammer F, Christoffel J, Seidlova-Wuttke D, Tezval M, Wuttke W, et al. Using the biomechanical properties of bone to compare Genistein, Resveratrol and 8Prenylaringenin as agent for preventing osteoporosis. Planta Med. 2008;74:794-801. [DOI:10.1055/s-2008-1074550]

8. Rezaie M, Azarbayjani MA, Peeri M, Hosseini SA. The Effect of Exercise, Ozone, and Mesenchymal Stem Cells Therapy on CB-1 and GABA Gene Expression in the Cartilage Tissue of Rats With Knee Osteoarthritis. Pharm Biomed
Res. 2020;6(1):45-52.

[DOI:10.18502/pbr.v6i1.3427]

9. Haghjoo M, Azarbayjani MA, Peeri M, Hosseini SA. Effect of Training, Hyaluronic Acid, and Mesenchymal Stem Cell Therapies on Osteocalcin Gene Expression in Cartilage Tissue of Rats with Knee Osteoarthritis. Gene, Cell Tissue. 2019;6(4). [DOI:10.5812/gct.98377]

10. Moreira LDF, Oliveira ML de, Lirani-Galvão AP, Marin-Mio RV, Santos RN dos, LazarettiCastro M. Physical exercise and osteoporosis: effects of different types of exercises on bone and physical function of postmenopausal women. Arq Bras Endocrinol Metabol. 2014;58(5):514-22. [DOI:10.1590/0004-2730000003374]

11. Abbasi T, Nazarali P, Hedayati M, Alizadeh R. The effect of eight weeks of high intensity interval training on osteoponetin and some bone mineral indices in young women. $\mathrm{J}$ Phys Educ Sport. 2018;18:532-5.

12. GardashiAfousi A, Khashayar P, Gaeini A, Choubineh S, Fallahi AS. Effect high intensity interval training on hormonal factors influence on bone metabolism. J Med Scie Razi. 2015;22(130):31-7.

13. Li F-H, Sun L, Zhu M, Li T, Gao H-E, Wu D$\mathrm{S}$, et al. Beneficial alterations in body composition, physical performance, oxidative stress, inflammatory markers, and adipocytokines induced by long-term high-intensity interval training in an aged rat model. Exp Gerontol. 2018;113:150-62.

[DOI:10.1016/j.exger.2018.10.006]

14. Peacock M. Phosphate Metabolism in Health and Disease. Calcif Tissue Int. 2020;1-13. [DOI:10.1007/s00223-020-00686-3]

15. Eliaz N, Metoki N. Calcium phosphate bioceramics: a review of their history, structure, properties, coating technologies and biomedical applications. Materials (Basel). 2017;10(4):334. [DOI:10.3390/ma10040334] 
16. Friedman MA, Bailey AM, Rondon MJ, McNerny EM, Sahar ND, Kohn DH. Calcium-and phosphorus-supplemented diet increases bone mass after short-term exercise and increases bone mass and structural strength after long-term exercise in adult mice. PLoS One. 2016;11(3): e0151995.

\section{[DOI:10.1371/journal.pone.0151995]}

17. Charoenphandhu N. Physical activity and exercise affect intestinal calcium absorption: a perspective review. Sport Med. 2007;7(1):171-81.

18. Scott JPR, Sale C, Greeves JP, Casey A, Dutton J, Fraser WD. Treadmill running reduces parathyroid hormone concentrations during recovery compared with a nonexercising control group. J Clin Endocrinol Metab. 2014;99(5):177482. [DOI:10.1210/jc.2013-3027]

19. Smith JK, Dykes R, Chi DS. The effect of long-term exercise on the production of osteoclastogenic and antiosteoclastogenic cytokines by peripheral blood mononuclear cells and on serum markers of bone metabolism. J Osteoporos.

2016;2016. [DOI:10.1155/2016/5925380]

20. Bitto A, Burnett BP, Polito F, Levy RM, Marini H, Stefano V Di, et al. Genistein aglycone reverses glucocorticoid-induced osteoporosis and increases bone breaking strength in rats: a comparative study with alendronate. $\mathrm{Br} \quad \mathrm{J}$ Pharmacol. 2009;156(8):1287-95. [DOI:10.1111/j.1476-5381.2008.00100.x]

21. Marini H, Minutoli L, Polito F, Bitto A, Altavilla D, Atteritano $\mathrm{M}$, et al. OPG and
sRANKL serum concentrations in osteopenic, postmenopausal women after 2-year genistein administration. J Bone Miner Res. 2008;23(5):715-20. [DOI:10.1359/jbmr.080201]

22. Li Y, Xing X, Wang H, Weng X, Yu S, Dong G. Dose-dependent effects of genistein on bone homeostasis in rats' mandibular subchondral bone. Acta Pharmacol Sin. 2012;33(1):66-74. [DOI:10.1038/aps.2011.136]

23. Hafez Dalia A. Anti-Osteoporotic Activity of Soy Total Extract and Genistein Compound in Ovariectomized RatsNo Title. J Am Sci. 2012;8(8):698-703.

24. Wu J, Wang XX, Takasaki M, Ohta A, Higuchi M, Ishimi Y. Cooperative effects of exercise training and genistein administration on bone mass in ovariectomized mice. J Bone Miner Res. 2001;16(10):1829-36. [DOI:10.1359/jbmr.2001.16.10.1829]

25. Hellings A, Buchan L, Castro M, St. Aubin $\mathrm{CR}$, Fisher AL, Al-Nakkash L, et al. Bone Strength Is Improved with Genistein Treatment in Mice with Diet-Induced Obesity. Curr Dev Nutr. 2019;3(11):nzz121. [DOI:10.1093/cdn/nzz121]

26. Nakajima D, Kim C-S, Oh T-W, Yang C-Y, Naka T, Igawa $S$, et al. Suppressive effects of genistein dosage and resistance exercise on bone loss in ovariectomized rats. J Physiol Anthropol Appl Human Sci. 2001;20(5):285-91. [DOI:10.2114/jpa.20.285]

\section{How to cite:}

Keikhosravi F, Daryanoosh F, Koushkie Jahromi M, Nemati J. The Effect of High Intensity Interval Training with Genistein on Biomechanical Properties of Femur Bone in Elderly Female Rats. Jorjani Biomedicine Journal. 2020; 8(1): 51-59. 